\title{
Las amas de cría en el corregimiento de Girona en el siglo XVIII: una interpretación sobre las causas de la lactancia de los niños expósitos
}

\author{
Miquel Borrell I Sabater
}

En el estudio de las amas de cría del corregimiento de Girona debe hacerse una clara distinción entre las amas mercenarias y las amas hospitalarias, tratándose en el presente trabajo de las segundas, que se dividirán en amas internas y amas externas. Las amas internas formaban parte del personal del hospital, concretamente de la «Comanda», nombre con el que se conocía la zona del edificio reservada a los expósitos, sin ningún contacto con los enfermos ni con las preñadas retiradas para salvar su honra.

A lo largo del siglo el número de amas internas osciló entre dos y cinco, siendo el de dos o tres el más común. El trabajo de estas amas consistía básicamente en dar de mamar a los bebés recién llegados al hospital mientras se les buscaba un ama externa para tenerlos en su casa hasta los dieciocho meses; asimismo, debían ocuparse de los niños que a esta edad eran devueltos al hospital al finalizar el contrato de lactancia:

«En el Hospital hay de continuo tres Amas que se ocupan de recibir y alimentar a los Niños que llegan a él, hasta que vienen de fuera otras a quienes se les entregan, encargándoles su particular cuidado, para cuyo fin se avisa frequentemente por todo el Obispado para que las mugeres que quieran criar niños acudan al Hospital, por el que se les da doce libras ardites anuales y veinte y quatro a las Amas que estan de continuo en él... ${ }^{1}$.

Las dificultades de las amas internas para atender un excesivo número de bebés fueron el caballo de batalla de los hospitales y casas de expósitos.

\footnotetext{
1 «Representación de D. ANTONIO BiLBAO al consejo sobre expósitos, resolución del Consejo e informe de muchos Prelados sobre la situación de los expósitos de sus diócesis". Biblioteca Nacional, Madrid, Ms 32/11.267, fol. 6 .
} 
¿Cómo amamantar a seis u ocho bebés como era necesario tantas veces? ¿Cómo cuidar a niños de dieciocho meses ofreciéndoles un mínimo de atención para no romper el ritmo que llevaban viviendo con las amas externas? Una palabra resumía el problema: dinero. Las amas internas no eran bien pagadas por el trabajo que realizaban. ¿Quién se iba a vivir al hospital ganando una libra mensual, cuando lactando al hijo de un zapatero o platero cobraban el doble, y sin moverse de su casa? Estas amas eran contratadas entre la escoria del mercado. Aquellas que por mal carácter, mal trato, escasa constitución física o su falta de moralidad eran repudiadas en el ambiente ciudadano, o bien las que para aguantar la leche mientras esperaban una crianza más provechosa, se ofrecían por unos días al hospital, creando siempre una situación de interinidad.

¿Cuál era la imagen que se tenía de estas amas? Todos los autores preocupados por el tema las consideraban la principal causa de mortalidad infantil: bastas, lujuriosas, sin sentimientos, interesadas solamente por su bienestar. ¿Tenían otra opción? ¿Les podía ofrecer algo más una institución empobrecida que la posibilidad de medrar a costa de las desgracias del prójimo? ¿Qué hacía mientras tanto la sociedad que tanto las criticaba? ¿Lactaban las madres a sus propios hijos para dejar libre el mercado al hospital? Por supuesto que no. ¿Se apoyaba económicamente a estas instituciones para aumentar el sueldo de las amas y conseguirlas en mejores condiciones? Pocas, muy pocas eran las aportaciones caritativas, de forma que figuraba este tipo de colaboraciones como un hecho extraordinario en el orden del día del Libro de Actas de la Junta del hospital de Sta. Caterina de Girona.

Un grupo de personas se ofrecen a doblar el sueldo de las amas internas, que pasarían a cobrar así 24 libras anuales, ofrecimiento aceptado por la Junta pero retocado, ya que de hecho lo que hicieron fue contratar una tercera ama para aliviar el trabajo de las dos fijas, dándoles, eso sí, una peseta diaria por cada niño más que se llevasen a su casa cuando los hubiera en exceso. También el 23 de enero de 1791 la Junta trató otro caso de una persona que ofrecía una peseta diaria para mantener un ama. Sólo dos ofrecimientos en el período comprendido entre el año 1753 y el 1791 no indican, precisamente, un exceso de caridad ${ }^{2}$.

Las pocas veces que se intentó subir el sueldo de las amas internas por la aportación de un particular, se creó un grave problema, ya que al

2 Archivo Histórico de Girona (AHG), Secció Hospital, «Libro resoluciones Hospital 1753 1791 ", Junta del 9 d'abril de 1785, fol. 183. 
enterarse las amas externas exigieron también su aumento, hecho que implicaba un desbordamiento del propósito inicial y una imposibilidad de resolver el problema, tal como pasó en el año $1793^{3}$.

\section{¿QUIÉN ERA EL AMA DE CRÍA?}

\section{El mercado de las amas de cría}

¿Quién era ama de cría? ¿Por qué una madre se dedicaba a este oficio? ¿Cuáles eran las razones que la llevaban a participar en el mercado de la leche?

«La muger que se pone a Ama o se le ha muerto su hijo, o le ha destetado ya o se le ha quitado antes de tiempo del pecho para darle a otro. En el primer caso es muy sospechosa por habersele muerto el hijo, o en el segundo caso, es mala, por tener la leche vieja; y en el tercer caso, que es el más freqüente, si para criar un hijo ageno abandonó el suyo, es mala madre, ¿cómo, pues, será buena Ama?" ${ }^{4}$.

Nadie se sentía culpable por alejarse de su hijo recién nacido, basta recordar ejemplos de padres que pasaron años sin ver a su hijo criado por un ama, a pesar de residir cerca del pueblo donde se criaba. ¿Por qué los dejaban? Los artesanos y pequeños mercaderes, por razones económicas, ya que la mujer solía trabajar en el taller o negocio y no podía permitirse el lujo de abandonar el trabajo, pagando, a veces con dificultades, la lactancia 5: el trabajo era seguro y el hijo tenía muchas posibilidades de morirse. Era más práctico pagar un ama y mantener el ritmo de producción que romper éste por un futuro incierto a corto plazo.

También abandonaban a los hijos por comodidad; autores contemporáneos se quejaban continuamente del egoísmo de ciertas damas que solamente se preocupaban de su aspecto físico y no aceptaban criar sus hijos, alegando pérdida de belleza, tenerse que despertar de noche, así

3 AHG, Secció Hospital, Llibre 244, fols. 1 i-1v.

4 BONELLS, JAUME, "Perjuicios que acarrea al género humano y al estado de las madres que rehúsan criar a sus hijos y medios para contener el abuso de ponerles un ama". Madrid 1786.

5 Bilbao, Antonio, Destrucción y conservación de los expósitos. ldea de la perfección de este ramo de Policia, modo breve de poblar la España y testamento de Antonio Bilvao. Antequera, 1789, págs. $47-48$. 
como pérdida de la capacidad sexual para engendrar nuevos hijos, hecho este último que servía para convencer al marido ${ }^{6}$.

Visto así, se creó una demanda que fue cubierta por las capas más bajas del espectro social. ¿Por dinero? ¿Para rentabilizar un bien natural? ¿Por caridad? ¿O por las tres razones juntas? Faltan estudios sobre el origen social de las amas y sus intenciones, pero en las muestras analizadas en el corregimiento de Girona, creo observar una superposición de intereses que hace pensar en una rebuscada complejidad en las causas de la lactancia hospitalaria. Por una parte parecen dejar de lado la simple aseveración de que las amas se movían a un nivel puramente económico, ya que podría existir una actividad eclesiástica que mentalizara a la mujeres para que lactaran expósitos, ensalzando el concepto de caridad cristiana como un deber hacia Dios representado en el huérfano abandonado. Esto podría explicar el hecho de que mientras habia quejas continuas por la escasez de amas internas (que funcionarían como personal fijo, con unas obligaciones laborales duras y estrictas), no ocurría lo mismo con las armas externas ${ }^{7}$.

\section{El espacio socio-económico del ama de cría externa}

¿Eran pobres las amas? Sí, sin lugar a dudas. $Y$ es por este motivo por lo que al concepto de caridad cristiana se añadía el premio: una libra catalana mensual. De aquí que las prédicas y consejos del cura de la parroquia encontraran un campo abonado. ¿Qué podía ofrecer el rico para satisfacer a Dios? Una caridad. ¿Qué podía ofrecer el pobre? Su cuerpo. Está claro que el mismo discurso hecho a una dama rica y a una mujer pobre tomaría distintos caminos: mientras la primera no aceptaría criar un extraño y traduciría en monedas el discurso, la segunda lo criaría porque disfrutaría indirectamente de la caridad dada por la primera, y ambas habrían cumplido con Dios.

No se puede poner en duda el aspecto crematístico de la lactancia, pero sin sacarlo de contexto. De la misma forma que J.L. Flandrin

\footnotetext{
6 "Las españolas cuyos medias económicos se lo permitian fueron siempre enemigas de criar a sus hijos y en consecuencia la figura de las amas se hizo indispensable en las familias acomodadas". SIMÓN PALMER, Ma CARMEN, «La higiene y la medicina de la mujer española a través de los siglos XVI-XIX" Actas de las Segundas Jornadas de Investigación Interdisciplinar, Universidad Autónoma. Madrid 1984, pág. 83.

7 Esta tarea del cura como intermediario está tratada por CAPPELLETTO GIOVANNA, «Infanzia abbandonata e ruoli di mediazioni sociale nella Verona del Settecento», Rivista Storica, $\mathrm{n}^{\circ} 53$. Bolonia, 1983.
} 
documenta amas mercenarias de bebés burgueses que llevaban años y años criando niños diferentes, no he encontrado en los libros del hospital una repetición constante de amas a lo largo de los años. Si lo hubieran hecho por motivos puramente económicos, ¿cómo es posible que al perder el segundo o tercer hijo no repitieran? ¿No tenían después necesidades económicas? ¿Cuál puede ser la causa de que hubiese amas que no hicieran de tales hasta haber perdido varios hijos? El simple pago de una libra mensual durante dieciocho meses no puede explicar estas actuaciones. Había algo más profundo: una mentalidad preparada por la parroquia, una línea subliminal de turnos casi forzados por rectores preocupados, y detrás, solamente detrás, la libra.

\section{TABLA 1}

OFICIOS DE LOS MARIDOS DE LAS AMAS EXTERNAS DEL HOSPITAL DE SANTA CATERINA DE GIRONA

\begin{tabular}{lcc}
\hline OFICIOS & AÑO 1738 & AÑO 1748 \\
\hline Trabajador & 27 & 32 \\
Bracero & 29 & 3 \\
Payés & 5 & 7 \\
Tejedor de lino & 4 & 3 \\
Herrero & 3 & 1 \\
Paraire & 1 & 5 \\
Carretero & 1 & - \\
Molinero & - & 1 \\
Carpintero & 1 & - \\
Hostalero & - & 1 \\
Espartero & - & 1 \\
Traginero & 1 & 2 \\
Sastre & - & 4 \\
Alfarero & 1 & - \\
Serrador & - & 1 \\
Soldado & 1 & 3 \\
Menestral & - & 3 \\
Albañil & - & 2 \\
Marchante & - & 7 \\
Sin especificar & 7 & 77 \\
\hline TOTAL & 72 & \\
\hline
\end{tabular}

FUENTE: AHG, Sección Hospital, Libros 391 bis i 391 tir. 
Las amas del hospital de Sta. Caterina de Girona eran pobres. Y el concepto de pobreza en el siglo xvill remite a la pura subsistencia. La Tabla 1 con los oficios de los maridos de las amas y la precariedad de los mismos lleva a pensar en una situación límite que una y otra vez debían rebasar para caer en la indigencia.

Se puede observar claramente la preponderancia de trabajadores y braceros, actividades, más que oficios, pendientes siempre de las fluctuaciones de las cosechas y la demanda, tanto en el campo como en la ciudad. En el primer caso sería la masa de jornaleros a sueldo fijo o pendientes de los diversos ciclos agrícolas, mientras que en la ciudad sería la mano de obra sin cualificar apta para cualquier trabajo que no requiriese conocimientos o técnicas muy precisas. En ambos casos, trabajos mal pagados e inseguros.

El resto de maridos entraria, en líneas generales, dentro de las actividades gremiales, con un reconocimiento social más elevado, pero con verdaderos problemas económicos la mayoría de las veces, debido al estacamiento gremial del xvIII que llevó a su paulatina desaparición absorbida por unas actividades comerciales e industriales que no dejaban espacio a unas estructuras cerradas y poco competitivas. A pesar de esto, hago notar que los artesanos y menestrales de la tabla representan ya la parte gremial más baja, la más extendida y por tanto menos importante, si exceptuamos los maestros de casas (albañiles) y los comerciantes (marxants), en aumento en la segunda serie.

Caso aparte merecería el estudio de los payeses, bastante representativos en las dos series, y con tendencia a aumentar. ¿De qué tipo de payés debemos entender que se trata? Se puede referir al payés enfitéutico, bien situado, con capacidad de creación y acumulación de excedente, que lacta un expósito para adoptarlo o por caridad, o bien nos podemos referir al payés masover, más precario la mayoría de las veces, en el que entraría el estímulo económico en mayor o menor grado. No obstante, las dos series trabajadas pueden servir para plasmar sincrónicamente el ambiente socio-económico de las amas: una situación baja, precaria y de subsistencia en la mayoría de ellas.

¿De qué manera la crianza incrementaba la economía familiar? Las amas cobraban a lo largo del siglo una libra catalana mensual y el hospital les proporcionaba también la ropa del bebé. Tenían que presentarse cada mes en el hospital para cobrar la póliza, o bien debían llevar al expósito para demostrar que estaba vivo, o presentar un certificado del rector informando del buen trato dado al bebé, que venía a ser como una fe de vida. 
Una libra mensual para alimentar al bebé. Un maestro de casas cobraba unas nueve libras mensuales y un bracero unas seis mensuales. Entonces el ama aportaba entre el diez y el veinte por ciento de los ingresos mensuales, cifra considerable si se considera que para lactar un bebé no se dejaba de hacer prácticamente ninguna de las tareas del hogar, incluso el trabajo del campo o el huerto, y que el gasto que representaba el bebé era mínimo. Sin duda, un buen sobresueldo, y más en una economía basada aún en muchos aspectos en el autoconsumo, donde cobrar en efectivo no era frecuente. Entonces hay que preguntarse por qué no repetían. No he visto una política prefijada del hospital para escoger amas: todas servían. No había una tendencia prefijada del hospital para escoger amas: todas servían. No había una tendencia a escoger las primerizas, no he encontrado ninguna norma que prohibiera repetir (algunas lo hacian), unas hacian de ama al morir el primer hijo, otras el segundo, etc, pero no repetían la experiencia. ¿Por qué? Esta sola constatación serviría para eliminar el motivo económico como elemento esencial de la crianza hospitalaria. ¿Por qué renunciar a un $20 \%$ de ingresos mensuales? Hay que volver a las mentalidades: un elemento que podría introducirse sería la frustración de la pérdida del hijo, sobre todo del primero. Otro elemento, más difícil de demostrar, sería la utilización de la lactancia como forma de control de la natalidad: aquella madre que perdía su hijo cogía un expósito para lactar y de esta forma retrasaba la próxima concepción dos años, tal como era habitual. Otra explicación, sería el paso de todas las amas a la lactancia mercenaria, hecho difícil de demostrar por falta de documentación, pero bastante improbable al analizar las secuencias decenales de las amas. Y otra posible razón podría ser la existencia de turnos organizados por los estamentos eclesiásticos (como ocurría en Galicia), lo que explicaría la no repetición.

\section{La familia de las amas de cría}

En las series de los años $1736-1743$ y $1786-1793$ se ha trabajado sobre un conjunto de pueblos caracterizados por su elevado número de amas ${ }^{8}$ y se ha seguido su historial familiar hasta que optaron por la lactancia hospitalaria. Al no tener constancia de cualquier otro trabajo en el cual se reconstruya la familia del ama, se hace imposible el análisis comparativo, que sería primordial para estudiar zonas y épocas (Tablas 2 y 3 ).

8 Los pueblos son Osor, Vilobi d'Onyar, Caldes de Malavella, Anglés, La Cellera de Ter, Sant Gregori y Cassà de la Selva. 
TABLA 2

NÚMERO DE HIJOS NACIDOS DE LAS AMAS ANTES DE LACTAR UN EXPÓSITO. SERIE 1736-1743 Y SERIE 1786-1793

\begin{tabular}{ccc}
\hline & \multicolumn{2}{c}{ NÚMERO DE AMAS } \\
\cline { 2 - 3 } HIJOS NACIDOS & $1736-1743$ & $1786-1793$ \\
\hline 1 & 27 & 16 \\
2 & 11 & 14 \\
3 & 11 & 6 \\
4 & 10 & 4 \\
5 & 8 & 2 \\
6 & 3 & 4 \\
S/i & - & 10 \\
\hline
\end{tabular}

FUENTE: Elaboración del autor a partir de los registros parroquiales.

TABLA 3

NÚMERO DE HIJOS MUERTOS DE LAS AMAS CUANDO EMPIEZAN A LACTAR UN EXPÓSITO. SERIE 1736-1743 Y SERIE 1786-1793

\begin{tabular}{ccc}
\hline & \multicolumn{2}{c}{ NÚMERO DE AMAS } \\
\cline { 2 - 3 } HIJOS MUERTOS & $1736-1743$ & $\mathbf{1 7 8 6 - 1 7 9 3}$ \\
\hline 1 & 27 & 21 \\
2 & 14 & 17 \\
3 & 4 & 2 \\
4 & 2 & 1 \\
5 & - & 1 \\
6 & 1 & 2 \\
s/i & 22 & 10 \\
\hline
\end{tabular}

TABLA 4

TIEMPO TRANSCURRIDO ENTRE LA MUERTE DEL HIJO DEL AMA Y LA LACTANCIA DEL EXPÓSITO

\begin{tabular}{lcccc}
\hline DÍAS & AMAS & $\%$ & AMAS & $\%$ \\
\hline & $1736-43$ & & $1786-93$ & \\
\hline $0-5$ & 7 & 19 & 13 & 42 \\
$6-10$ & 4 & 11 & 3 & 10 \\
$11-15$ & 6 & 16 & 4 & 13 \\
$16-20$ & 3 & 8 & 2 & 7 \\
$21-25$ & 3 & 8 & 4 & 12 \\
$26-30$ & 1 & 3 & - & 16 \\
$31-60$ & 6 & 16 & 5 & - \\
$>60$ & 3 & 8 & - & - \\
s/i & 4 & 11 & - & - \\
\hline
\end{tabular}

FUENTE: Elaboración del autor a partir de los registros parroquiales. 
Se constata en las dos series la tendencia general de dos años de duración entre el nacimiento de los hijos, así como la existencia de familias reducidas a pesar de la alta natalidad, compensada con una fuerte mortalidad. ¿Cuándo hicieron de amas? De las 126 amas de las dos series, 43 cogieron un expósito al morirse su primer hijo. ¿Por qué no se colocaron en el mercado libre? ¿Sería quizás porque no tenían la intención de convertirse en amas mercenarias, profesionales, y se limitaban a aprovechar, a rentabilizar por una vez su leche? Hay que considerar esta hipótesis: no puede perderse un don de Dios, un alimento natural producido en unas circunstancias especiales. En una sociedad con escasos excedentes este pensamiento debía estar muy enraizado, y casos hay de amamantar a niños mayores o abuelos para no perder la leche. Si a esto se añade una constante prédica parroquial captando adictas para cumplir con la caridad, podría empezar a entenderse la mentalidad de la nodriza como un fenómeno más ideológico que económico: aprovechar los bienes de Dios y cumplir con el precepto de la caridad cristiana se convertirian así en elementos esenciales de la lactancia.

¿Cómo eran las familias de las amas? Lo primero que se observa es la preponderancia de amas jóvenes y con pocos hijos (Tabla 4). En las dos series las amas con uno o dos hijos nacidos representan más del $50 \%$. Este hecho podría corroborar la hipótesis de la frustración maternal como un elemento más de la lactancia no profesional. También debía influir el tiempo libre, entendido no como ocio, sino como posibilidad de dedicación a las faenas de la casa y la huerta, actividad más complicada si había un elevado número de pequeños a los que cuidar. Así, no es extraño que baje el número de hijos de las amas. No obstante, hay que considerar que estos hijos nacidos no eran siempre hijos vivos: un caso extremo sería el de Francesca Tordera, de la Callera de Ter, que entre el año 1726 y 1738 parió seis hijos y todos se le murieron y que no lactó un expósito hasta la muerte del último. ¿Podemos pensar que lo hacía por dinero? Rotundamente, no. O María Baus, de Caldes de Malavella, a la que se le murieron los seis hijos paridos entre 1771 y 1792 y que lactó a dos expósitos que, desgraciadamente, también se le murieron. ¿Necesidad de dinero o necesidad maternal? ¿Y por qué no un intento desesperado de renovación generacional?

Queda clara, entonces, la circunstancia que llevaba a la lactancia: la muerte de un hijo con el consiguiente aprovechamiento de la leche. Las dos series son explícitas: el 66,1\% de las amas cogen el expósito cuando se les ha muerto un hijo propio y del $33,9 \%$ restante no hay información fidedigna en los registros parroquiales, a pesar de creer que seguían la misma pauta (falta de información se considera cuando en los libros pa- 
rroquiales no figura la fecha de nacimiento del propio hijo - la mayoría- o tampoco la de la muerte del propio hijo - la minoría - que sí podría hacer pensar en una lactancia profesional) ${ }^{9}$.

Así, parece demostrado que no se mercadeaba con la leche y que las amas hospitalarias no actuaban dando su leche porque la quitaban de su hijo vivo, subalimentando así al propio y al extraño, sino para aprovechar la propia antes de perderla. Estos datos demuestran también que las amas hospitalarias no hacían una lactancia corta para coger otro bebé, hecho bastante corriente en las amas mercenarias, y que implicaba también una negligencia en la alimentación y una despreocupación hacia el recién llegado, tema denunciado constantemente debido a la alta mortalidad que se registraba entre las amas mercenarias. «Según el cálculo de algunos autores, de muchos niños que mueren antes de la edad de tres años, más de la mitad son los que han criado mujeres extrañas" ${ }^{10}$.

Otro hecho podría corraborar esta hipótesis: la pequeña mortalidad entre los bebés cuidados por amas hospitalarias externas. En las diez series que abarcan todo el siglo de todo el corregimiento de Girona, mueren el $38,8 \%$ de los expósitos lactados por las amas en los primeros dieciocho meses de su existencia, cifra no excesivamente alta si se compara con la mortalidad de los legítimos y mejor cuidados, y si se consideran las negativas condiciones en que nacieron y pasaron los primeros dias de su vida. No, las amas externas no eran las culpables de la mortalidad de los expósitos. ¿Qué posibilidades tenía de sobrevivir el 32,5\% de los expósitos que tardaban entre 0 y 15 días entre su nacimiento y su entrega a un ama? ¿O el $24,9 \%$ que tardaba entre 14 días y un mes? ¿O el $34,4 \%$ que tardaba más de un mes? Estos datos del año 1708 , que se repiten con altibajos a lo largo del siglo, indican claramente el handicap de salida de estos infantes y sus escasas posibilidades de supervivencia, hecho que hace valorar positivamente la tarea de las amas externas, y que nos debe hacer pensar en una gran diferencia de mentalidad entre ellas y las amas mercenarias tan atacadas por médicos e ilustrados (Tabla 5).

9 En Turín el $70 \%$ de las amas lo hacían cuando se les moría su propio hijo para rentabilizar la leche, no como trabajo fijo: CAVALLO, SANDRA, "Strategie politiche e familiari intorno al baliatico. II monopolio dei bambini abbandonati nel Canavese tra Sei e Setecento", Rivista Storica, n 53. Bolonia 1983, pág. 409.

10 AMR Y BoRbón, Josefa: “Discurso sobre la educación física y moral de las mujeres". Madrid, 1790. 
TABLA 5

DIAS DE TARDANZA ENTRE EL BAUTIZO Y EL INICIO DE LA LACTANCIA, NÚMERO DE EXPÓSITOS Y VALORES PORCENTUALES 1708-1708

\begin{tabular}{|c|c|c|c|c|c|c|c|c|c|}
\hline \multirow{3}{*}{$\begin{array}{l}\text { AÑO } \\
1708\end{array}$} & \multicolumn{2}{|c|}{ 0-5 DIAS } & \multicolumn{2}{|c|}{ 5-15 DIAS } & \multicolumn{2}{|c|}{ 15-30 DÍAS } & \multicolumn{2}{|c|}{ 30-60 DÍAS } & \multirow{2}{*}{$\frac{+60 \text { DIAS }}{\text { Exp. } \%}$} \\
\hline & \multicolumn{2}{|c|}{ Exp. $\%$} & \multicolumn{2}{|c|}{ Exp. \% } & \multicolumn{2}{|c|}{ Exp. \% } & \multicolumn{2}{|c|}{ Exp. \% } & \\
\hline & 11 & 21,5 & 6 & 11,7 & 13 & 25,4 & 11 & 21,5 & $10 \quad 19,6$ \\
\hline 1718 & 38 & 38,7 & 32 & 32,2 & 19 & 19,2 & 3 & 3,0 & $6 \quad 6,1$ \\
\hline 1728 & 6 & 6,9 & 34 & 39,5 & 26 & 30,1 & 17 & 19,6 & 3,4 \\
\hline 1738 & 8 & 12,9 & 22 & 35,4 & 22 & 35,4 & 6 & 9,6 & 6,4 \\
\hline 1748 & 24 & 15,6 & 17 & 30,8 & 7 & 12,6 & 6 & 10,8 & 1,8 \\
\hline 1758 & 16 & 34 & 15 & 31,9 & 8 & 17 & 6 & 12,7 & 4,2 \\
\hline 1768 & 14 & 32,5 & 17 & 39,5 & 8 & 18,6 & 2 & 4,6 & 4,6 \\
\hline 1780 & 20 & 35 & 19 & 33,3 & 11 & 19,2 & 6 & 10,3 & 1,7 \\
\hline 1788 & 15 & 26,3 & 17 & 29,8 & 8 & 14 & 11 & 19,2 & 610,5 \\
\hline 1798 & 14 & 25,4 & 18 & 32,7 & 11 & 20 & 11 & 20 & $1 \quad 1,8$ \\
\hline TOTAL & 166 & 27,1 & 197 & 32,2 & 133 & 21,7 & 79 & 12,9 & 36 \\
\hline
\end{tabular}

FUENTE: Elaboración del autor a partir de los «llibres de Dides», AHG.

\section{EL CONTROL DE LAS AMAS DE CRÍA}

¿Qué control ejercía el hospital de Sta. Caterina de Girona sobre sus amas hospitalarias externas? Toda la documentación interna, así como las pragmáticas y opiniones de los ilustrados insistían en un punto crucial: debía vigilarse que las amas no fueran las propias madres. Este hecho que, por documentado, debía ser normal, indica una vez más que el abandono afectaba a las madres casadas, de pocas posibilidades económicas, que abandonaban y pretendían recuperar el bebé para amamantarlo cobrando la mensualidad, ya que es muy difícil creer que se tratara de madres solteras, preocupadas por esconder el parto, las que después lactasen a un expósito. Vuelve a surgir el dilema de hijos ilegítimos versus hijos de la pobreza.

«...consultará al Director en los casos que lo exijan, celará sean tratados y asistidos devidamente y que no se suplante otra criatura en lugar del Expósito, ni que las verdaderas madres se los lleven para lactar habiendolos expuestos con esta idea movidas del lucro del salario, y si llega el caso de 
averiguarse este exceso lo comunicará al Director para tomar la Providencia correspondiente" ${ }^{11}$.

"Los Párrocos y los Ecónomos de las demarcaciones y partidos pondrán todo cuidado en que no se den para lactar y criar Expósitos a mugeres que verosimilmente sean sus propias madres, lo que seria ocasion a que fuera enorme la multitud de Expositos, siguiendose gastos insoportables" ${ }^{12}$.

El sistema de control utilizado por el hospital de Sta. Caterina consistía en un libro donde se apuntaban todos los datos relacionados con el ama y el expósito: diferentes pagos que se hacian al ama, así como con los cambios de ama y el retorno o adopción del expósito una vez terminados los dieciocho meses de la lactancia.

Los administradores del hospital exigían unas determinadas condiciones: cada mes el ama debía ir al hospital a cobrar la mensualidad llevando la criatura para comprobar si realmente estaba viva, o en su defecto, daban la confianza y responsabilidad al cura del pueblo que otorgaba una fe de vida:

"Item que quan vingan las didas per cobrar las mesadas y per algun impediment no pugan portar las criaturas, degan aportar de son Rector, vicari o altre en son lloch una fe com las tals criaturas estan bonas y sanas no altrament [...] Item que se advertesca a ditas didas quant sen portaran las critaruras que no passan de tres messos en venir asercar las mesadas, y que si als quatra mesos no son vingudas, se fasa la averiguatio ab las altras didas del mateix lloch si dita criatura es morta o ques de ella, perque altrament no pot constar en los llibres del dit hospital de las tals criaturas, y es cosa molt important per las criaturas y per lo hospital, en los devinidors 13 .

«...facilitará el pronto pago de los salarios mensuales de las Amas quienes para cobrarlos deveran traer dicho impreso y una certificacion del propio Párroco que diga vivir el Exposito tal, o haver muerto en tal dia, cuia certificacion precisa a impedir todo fraude..." ${ }^{14}$.

De todo este control se hizo eco la Real Cédula de 1796 que reglamentaba todo el sistema de organización y cuidado de los expósitos, y que en el artículo 13 se preocupaba por el control de las amas y de los expósitos:

\footnotetext{
11 Archivo Municipal Girona (AMG), V. 1.1., Legajo 2, año 1803, «Expósitos. Nota de lo que necesitarán...", art. 7è.

12 «Real Cédula de S.M. por la que manda observar el reglamento inserto para la policía general de expósitos...", año 1796, art. 16.

13 Sección Hospital, Libro 134, Amas de Expósitos 1702-1709, contraportada.

14 V.1.1., legajo 2, año 1803; op. cit, "Expósitos...", art. 2.
} 
"Se han de presentar las Amas con los Expósitos al Ecónomo del partido en los tiempos que fuessen señalados para cobrar el estipendio, llevando certificación dada por el Párroco y alguno de los Alcaldes del pueblo donde se lactan y crian los Expósitos, en cuya certificación se expresará el nombre del Ama y del Expósito, y que este no ha fallecido; con lo cual se evitarán equivocaciones, y que se suplante otra criatura en lugar del Expósito" ${ }^{15}$.

Las alzas provocadas por las carestías y guerras perjudicaron enormemente los salarios de las amas que vieron cómo, acabada la Guerra Gran, la inflación convirtió su escasa paga en una aportación simbólica:

«En los tiempos antiguos se señaló por salario de las Amas forasteras diez reales mensuales y con el acudian completamente quasi quantas se necessitaban, porque lo estimaban tal cual proporcionado al corto valor que tenian entonzes los Alimentos, pero haviendo tomado estos el incremento tan considerable, como es notorio, son un numero limitadissimo las que se presentan, sin embargo de la incesante solicitud de esta Junta, y de las continuas suplicas y amonestaciones de los reverendos Curas Parrocos para inclinar y estimular la caridad» ${ }^{16}$.

La Junta estaba convencida de que subiendo los sueldos vendrían más amas y solicitó ayuda al colector general de Espoleos para poder aumentar de diez a doce o quince reales mensuales y así salvar más expósitos que fueran útiles al Estado. Es importante observar la fecha de la queja y petición: 14 de setiembre de 1796, rehaciéndose el corregimiento de Girona de la Guerra Gran.

\section{EL ORIGEN GEOGRÁFICO DE LAS AMAS DE CRIAA}

El determinismo geográfico juega un papel esencial en el repartimiento por municipios de las amas a lo largo del siglo xvill. Se ha realizado un vaciado del lugar de origen de las amas a partir de los libros del hospital y del hospicio de Girona correspondientes a los años 1708-1718, 1735$1741,1758-1767$ y 1786-1795, series que pueden considerarse suficientemente amplias y representativas del siglo.

Sirve para constatar la primera hipótesis de trabajo: el hospital escogía las armas más próximas geográficamente a Girona, empezando por las de la misma ciudad. Cogiendo como centro la ciudad de Girona se observa que queda rodeada de municipios con un nombre decreciente de amas

15 Op. cit., «Real Cédula...", 11 desembre, 1796, art. 13.

16 AHG, Sección Hospital, libro 244, folio 5 i-5v, año 1798. 
a medida que se alejan de la capital, quedando rodeado este primer núcleo por otro al norte y sur que cierra la geografía de las amas, con unas cifras que oscilan entre 0 y 15 amas, quedando fuera del mercado toda la plana del Empordà y la marina.

Este determinismo geográfico, hasta cierto punto lógico si se considera que el ama tenía que ir cada mes a cobrar y enseñar el niño, presenta a mi entender, unas características especiales: sí a la proximidad geográfica, pero, ¿por qué no es concéntrica? En el mapa se observa la preponderancia de una determinada zona de influencia, el llamado «eje del río Ter montañoso" que hace que St. Gregori, Amer, Bescanó, Anglés y Osor acaparen el $36,6 \%$ de todas las amas de las cuatro series (684 del total de 1868), y si a estos núcleos añadimos Quart d'Onyar, Vilobi d'Onyar, La Cellera de Ter, St. Martí de Llémena y les Planes de Hostoles, acaparan el $50 \%$ de las amas. O sea, el río Ter y la montaña serían los dos elementos diferenciadores a la hora de escoger las amas, o de ofrecerse éstas. ¿Por qué razones? ¿Por qué había pocas amas en el Baix Empordá, zona sin dificultades de comunicación con Girona? Y lo mismo sucedía con todo el sur del Alt Empordá y el Pla de l'Estany, así como toda la plana de La Selva. ¿Qué razones llevaron a abrir y usar este eje del Ter? ¿Se puede hablar de clientelismo? Hay que recordar que el hospital tenía propiedades en La Cellera de Ter, propiedades importantes que se usaban para aprovechar el agua del río y construir molinos, pero el resto de municipios no pueden significar más que otros en el número de propiedades o censos o censales que tenía el hospital, o sea que se hace difícil, con la documentación actual, ir más lejos en esta hipótesis ${ }^{17}$.

Otra explicación vendría dada por el tipo de propiedad de la tierra: el eje, a medida que se adentra al oeste, representa un tipo de propiedad más amplia. Los bosques de Osor han tenido siempre pocos propietarios con grandes extensiones: la explotación del bosque requiere grandes extensiones para que resulte rentable y la agricultura de secano o de regadío es inexistente, con la presencia de simples y pequeños huertos de autoconsumo. Entonces, en estos municipios, se encuentran pocos payeses propietarios o enfitéuticos y sí muchos jornaleros y braceros sin propiedades. La tierra está repartida entre pocos y el resto vive del jornal. En estos municipios es donde se pueden encontrar amas que ayudarían a la economía familiar.

17 Este clientelismo ha sido demostrado en la zona del Canavese italiano por SANDRA CAVAllo, op. cit. donde se origina un verdadero monopolio de la crianza hospitalaria a partir de las influencias y relaciones de los señores de la zona con el hospital de Turín. 
Una tercera posible causa serían las constantes afirmaciones médicas alabando el clima seco de montaña para la salud de los bebés, hecho que llevaría a esta tendencia al hospital de Sta. Caterina de Girona, pero del que no consta ninguna alusión en la documentación trabajada.

O sea que para explicar el origen de las amas se puede hablar de una influencia de la proximidad geográfica (primer nivel de concreción), pero matizada por causas de tipo social (clientelismo), económico (distribución de la tierra) sanitario (clima) y orográfico (montaña-llano-marino), que formarían el segundo nivel de concreción, entremezclándose en distintas proporciones.

\section{LAS TRAMPAS DE LAS AMAS DE CRÍA}

\section{Las trampas sociales}

Normalmente, por necesidades económicas o fisiológicas, el ama escondía la verdad o parte de la misma a la dirección del hospital, lo que era fácil de hacer si se considera que ésta no estaba en condiciones de exigir excesivas cualidades a las amas, limitándose a aprovechar las que se ofrecían. ¿Sabía la institución si la futura ama lactaba aún hijos propios? ¿O si era la misma madre que había abandonado el bebé e iba a buscarlo para cobrar su propia lactancia? Para los administradores del hospital era muy difícil controlar la vida y actividades de las amas, y de aquí provenían muchas críticas.

Los casos más frecuentes y documentados corresponden a las amas que habían abandonado a su propio hijo, como denunciaba el obispo de Córdoba: «Hay muchas madres que exponen sus hijos por tomar otros para criarlos y tomar el estipendio, y apenas hay mes que no se vuelvan hijos legítimos a sus padres» ${ }^{18}$. También Antonio Bilbao delataba a las amas que iban a buscar un expósito mientras aún lactaban a su propio hijo ${ }^{19}$ y Antonio Arteta incidía en la misma trampa al afirmar que «... acostumbran muchas a ocultar que tienen criatura suya, a la que están lactando al mismo tiempo: de lo que se dexa entender la leche que le darán al expósito, al que solamente procuran se mantenga con vida a fin de lograr el estipendio de la casa...» 20

\footnotetext{
18 «Representación de D. Antonio de Bilbao al Consejo sobre expósitos, resolución del Consejo, e informes de muchos prelados sobre la situación de los expósitos de su diócesis", Biblioteca Nacional, Madrid, Mss 32/1.1267, folio 52.

19 BILBAO, ANTONIO, op. cit., pág. 199.

20 ARTETA, ANTONIO, Disertación sobre la muchedumbre de niños que mueren en la infancia y modo de remediarlo y de procurarles sus cuerpos. Zaragoza 1802, 1a parte, págs. 90-91.
} 
o bien «... porque habiendo supuesto cuando la reciben (el bebé), averles muerto los hijos que criaba y que por esta razón se dedica a semejante empleo, prosiguen alimentando a sus hijos, dividiendo la leche en dos alumnos... ${ }^{21}$ llegando al extremo denunciado por Jaume Bonells de que a veces el ama podía llegar a cambiar su hijo por el que lactaba ${ }^{22}$.

Otras trampas consistían en que las amas, sabiéndose embarazadas o enfermizas, cogían un expósito para cobrar un sueldo o para sacarse la enfermedad de su cuerpo («... codiciosas... mujeres pobres y enfermas, de poca leche...» que hacían presentarse al hospital a una saludable a revisión, pero después ellas se quedaban con el niño, hecho criticado por fray Tomás de Montalvo ya que «si quieren escusarse a título de pobres y que soliciten la nutrición del infante para alivio de su penuria, también se engañan, porque nos es lícito pretender la utilidad propia con daño ageno» ${ }^{23}$. En todos ellos había un engaño premeditado, una utilización egoísta de la lactancia en beneficio propio. En estos casos, no muy numerosos pero bien aireados, el concepto de caridad era inexistente y el aprovechamiento de una situación desesperada por parte del hospital les permitía actuar impunemente ${ }^{24}$.

Otro caso de engaño sería el de aquellas amas que escondían la muerte del expósito para ir cobrando la mensualidad, de los que sólo he encontrado un ejemplo en las diez series, ya que el control del cura no permitía esconder mucho tiempo el óbito.

Uno de los hechos más denunciados era precisamente la escasez de leche o la baja calidad de la misma, por debilidad del ama o por ser una leche demasiado vieja, pero si el ama estaba decidida a llevarse al expósito, encontraba excusas suficientes para conseguirlo:

«Altres didas se presentan sens escrúpol tenint una llet molt vella, y si se subsona de la mala qualitat de la llet dissimulan dient que la fatiga del camí ha fet ly haurà alterada la llet...» ${ }^{25}$.

¿Qué relación puede establecerse entre las amas que abandonaban la lactancia y las trampas sociales? ¿Por qué dejaban al expósito antes de

\footnotetext{
21 Fray Tomás de Montalvo, Práctica política y económica de expósitos en que se descubren su origen y calidades, resolviéndose las dudas que pueden ofrecerse en esta materia y juntamente se declara el govierno doméstico que en sus Hospitales se debe observar. Granada 1701, pág. 568.

22 Bonells, Jaume, op. cit, pág. 357.

23 Fray TOMÁs de MONTAlvo, op. cit., pág. 565.

24 AHG, Sección Hospital, Caja 49, «Muy señor mio, con fecha 9 de junio...».

25 Textos mèdics catalans. Pediatria i obstetricia al segle XVIII». Ripoll, 1989, pág. 52.
} 
acabar los dieciocho meses? Una primera explicación, la más eleniental, vendría dada porque el ama conseguía una lactancia mercenaria, más rentable. No se puede demostrar por falta de datos y queda como una hipótesis de trabajo que serviría para entender la lactancia hospitalaria como un sucedáneo de la mercenaria, un compás de espera para aguantar la leche hasta conseguir una mejora económica.

Una segunda explicación vendría dada por el embarazao del ama que no le permitiría mantener al expósito, a pesar de las trampas que se hacían con la alimentación artificial. A pesar de ser una buena posibilidad, no se ha encontrado en la reconstrucción familiar de las series 1736-1743 y 17861793, ningún ama de las que hubiese abandonado al expósito que bautizara a su hijo en los meses siguientes, lo que significaría que habiendo casos, no representarian un número elevado.

Una tercera posibilidad, ya personal, sería una enfermedad del ama o quedarse sin leche, aunque es creíble que pocas amas actuarían con esta nobleza, ya que constantemente había quejas de amas que contagiaban sus enfermedades:

"Se tróban altres didas infectadas de ronya, de brians y altres vicis cutáneos, que ellas repercuteixen per algun temps rentant-se ab una decocció de tabac o altre [...] de aquí ve lo veurer tantas criaturas infectades de vicis [... Altres (y no és raro) són infectadas del mal venéreo y insinuan aixis ab la llet est mal a las criaturas [...] Ditas donas saben tant bé y ab la major trassa ocultar llur estat del qual no pot percebir-se indici algun..." ${ }^{26}$.

De los 622 expósitos estudiados, hay 145 que cambiaron de ama a lo largo de su lactancia (Tabla 6), representando un $23,4 \%$ del total y los libros del hospital de Girona no consignan la causa del abandono, excepto dos casos donde habla de enfermedad del ama. ¿Se puede deducir que el resto entrarían a tormar parte de las trampas sociales? Habría de ser para pasar a una lactancia mercenaria, puesto que el embarazo parece demostrado que no influía. Varios autores denunciaron precisamente este compás de espera para rentabilizar la leche, aunque no es creíble que una familia dispuesta a pagar una lactancia privada se conformarse con una leche vieja para su bebé, a menos que formara parte de las clases artesanas y trabajadoras y tuviera necesidad de la misma. 
TABLA 6

ESTABILIDAD DE LA LACTANCIA 1708-1798

Estadística del $n^{\circ}$ de expósitos que acaban la lactancia con la misma ama que les había cogido por primera vez, $\mathrm{n}^{\circ}$ de expósitos que mueren durante la lactancia con amas externas, $n^{\circ}$ de expósitos que cambian de ama y $n^{0}$ de expósitos muertos.

\begin{tabular}{cccccc}
\hline AÑO & ACABAN & MUEREN & CAMBIO & TOTAL & ADOPTS. \\
\hline 1708 & 45 & 7 & 0 & 52 & 2 \\
1718 & 52 & 25 & 22 & 99 & 9 \\
1728 & 51 & 14 & 21 & 86 & 4 \\
1738 & 28 & 18 & 18 & 64 & 1 \\
1748 & 29 & 16 & 12 & 57 & 0 \\
1758 & 15 & 28 & 5 & 48 & 0 \\
1768 & 2 & 34 & 7 & 43 & 0 \\
1780 & 21 & 25 & 11 & 57 & 0 \\
1788 & 15 & 30 & 12 & 57 & 1 \\
1798 & 0 & 38 & 21 & 59 & 0 \\
\hline TOTAL & 258 & 235 & 129 & 622 & 17 \\
$\%$ & $41,4 \%$ & $37,7 \%$ & $20,7 \%$ & - & $2,7 \%$ \\
\hline
\end{tabular}

FUENTE: Elaboración del autor a partir de los «llibres de Dides», AHG.

\section{Las trampas higiénico-sanitarias}

Entrarian en este grupo todas aquellas actividades, omisiones, dejadez de las amas en el cuidado del bebé, producto de su status social y de sus necesidades de continuar realizando unas actividades caseras que no podían posponerse (el campo, la huerta, el trabajo a destajo, etc). Entonces, el ama jugaba con la ventaja de organizarse a su aire la cría del bebé, sin estar controlada por nadie, ya que mientras demostrase que el expósito estaba vivo, nadie se preocuparía de averiguar cómo era la crianza. Ya aquí prodría continuarse la controversia entre ama mercenaria y ama hospitalaria. La primera era la que recibía las críticas más feroces, la que vivía de las trampas que no dejaban de ser formas de vida. ¿Y cuáles eran estas trampas? La lista es bantante larga, pero vale la pena comentarla para observar la forma de crianza de los bebés: 
«En sus casas en donde las nodrizas, lejos de quien las zele, despliegan los velos de su mala condición y sueltan la rienda a su destemplanza y su impaciencia, a su furia y crueldad. Allí es donde las pobres criaturas experimentan y sufren los deplorables efectos de la ignorancia y la desidia, de la insensibilidad y vileza de las Amas. [...] Ya sea por miseria, ya por codicia, el principal objeto del Ama es socorrerse a sí y a su familia. El campo, la huerta, el ganado, las faenas caseras, el gobierno de los chiquillos, etc apenas le dexan lugar de atender a las necesidades del niño que cría..." ${ }^{27}$.

Y el niño gritaba, hacía sus necesidades, y si el ama le oía, le aturdía a gritos y si no le oía, el niño pasaba hambre. Después, cuando el ama tenía los pechos cargados de leche y le hacían daño, le daba de mamar para aligerarse ella y no para contentar al bebé. Otras veces no eran las faenas de la casa, sino el cumplimiento de relaciones sociales y la ligereza de las amas las que llevaban al mismo final: malestar del niño, hambre, nervios:

«Algunas, siendo mozas de buen pasear y pobres, cualidades que engendran sospecha de liviandad [...] y mugeres pobres y hermosas no siempre son honestas, no asisten a los alumnos, acostumbran dejarlos solos para no perder sus pases [...] y los infantes necesitados de alimentos los piden con clamores continuos llantos [...] y se arrojan de sus camillas y padecen graves infortunios... 28 .

¿Cuál era la solución? Enfajarlos. Éste fue otro vicio de las amas, que también usaban las madres legítimas del siglo xVIII: «Apenas són nadas que ja las oprimeixen, las allargan o estiran los brassos y camas, las embulican de tantas cosas de modo que ellos no poden mudar de positura" ${ }^{29}$.

El sistema de enfajarlos para evitar sus movimientos estaba extendido por todo el país y era una solución para poder realizar todas las tareas domésticas en la seguridad de que el infante no tendría posibilidades de moverse, con todos sus miembros pegados al cuerpo, hecho que provocaría la deformación de diversas partes de su cuerpo y de las articulaciones, engrosando y acortando las piernas e irritando la piel, oprimiendo la circulación y provocando sofocaciones y flaquezas que podían desembocar en la muerte, como así lo afirmaba el doctor Pere Puig el año 1786 y también denunciaba Jaume Bonells ${ }^{30}$. Uno de los vicios denunciados por el doctor

\footnotetext{
Bonells, Jaume, op. cit, págs. 148 y 158.

Fray Tomás de Montalvo, op. cit., pág. 571.

Textos mèdics catalans, op. cit., pág. 55.

Bonells, Jaume, op. cit., pág. 198.
} 
Pere Puig, pero también por otros escritores de la época, era la falta de higiene del ama que no limpiaba al bebé y éste malvivía entre sus excrementos dos o tres días, con la posibilidad de coger divesas infecciones o enfermedades, o bien la costumbre de masticar el ama el alimento del bebé antes de dárselo, con el peligro de contagiarle enfermedades a través de la saliva. Otra crítica, muy generalizada, era la costumbre de dormir el ama y el niño en la misma cama y al darle de mamar dormida había grandes posibilidades de ahogarlo. Conviene recordar que éste fue uno de los sistemas utilizados en distintas zonas para deshacerse de los niños, lo que J.L. Flandrin ha documentado en Francia como un método legal de infanticidio.

La última crítica que hacía Pere Puig a las amas era la excesiva utilización de drogas para hacer dormir de noche a los bebés cuando lloraban por cualquier circunstancia: la triaca magna, la discordium y el jarabe de opio eran utilizados por las amas sin miramientos, provocando a la larga convulsiones y vértigos que Lloyd Demause documenta ampliamente:

«El Dr. Hume se quejaba en 1799 de que miles de niños morían todos los años porque las nodrizas siempre estaban haciéndoles tragar "Godfrey's Cordial" que es un opiáceo muy fuerte y en definitiva tan fatal como el arsénico. Afirman que to hacen para hacer callar al niño, y desde luego así muchos se quedan callados para siempre...» ${ }^{31}$.

\section{CONCLUSIONES}

Parece bastante claro que el funcionamiento de las amas de cría se aparta de la clásica y única explicación economista: la fuerza de la iglesia, a nivel de persuasión y/o coacción sería un buen motivo dónde encontrar a las amas de cría hospitalarias, mujeres de familias pobres, quizás no decididas a criar, pero inmersas en unas redes sociales que no les dejarían otra salida que esta aplicación de la caridad cristiana rentabilizando la leche al perder a su propio hijo. La libra mensual sería el efecto, no la causa, de su decisión.

31 LloYd, Demause, Historia de la infancia. Madrid, 1982, pág. 65; incluye también una amplia relación de drogas dadas a los niños. 